\title{
SPONTANEOUS REGRESSION OF LUMBAR DISC HERNIATIONS
}

\author{
(1) Aykut AKPINAR', (1) Nevhis AKINTÜRK², (1) Bekir Mahmut KILINÇ1', (1) Metin KASAP1 \\ ${ }^{1}$ University of Health Sciences Turkey, Haseki Training and Research Hospital, Clinic of Neurosurgery, İstanbul, Turkey \\ ${ }^{2}$ Ege University Faculty of Medicine, Department of Neurosurgery, Izmir, Turkey
}

\begin{abstract}
Objective: Lower back and back pain are among the most common disease symptoms. On the other hand, herniated nucleus pulposus (HNP) is a common condition that triggers radiculopathy or myelopathy. If radiculopathy affecting the foot occurs concurrently with back pain, the patient is very likely to have lumbar disc herniation. Medical treatment, bed rest and physical therapy are primarily recommended to patients with radicular pain. This study aimed to describe the factors associated with spontaneous disc regression.

Materials and Methods: Patients who were admitted to the outpatient clinic with lower back and leg pain were closely followed-up. After magnetic resonance imaging (MRI) scans revealed lumbar (HNP), a conservative medical treatment was recommended. When the patients' radicular pain disappeared or neurological exams became normal, control MRI scans were done. Then, we retrospectively reviewed these patients. Results: We detected a total of 12 patients with lumbar disc regression, including six males and six females, in the last 3 years of follow-up. The mean age of the patients was $41.83 \pm 6.83$. LHNP was present at the L4-5 space in five patients and at the L5-S1 space in seven patients. Eight $(62.5 \%)$ of the patients had sequestrated disc herniation, while four had subligamentous disc herniation. Four of the sequestrated discs were upmigrated, and four of them were down-migrated. The mean time to pain disappearance of the patients was $2.33 \pm 1.23$ months.

Conclusion: A conservative treatment and bedrest are primarily recommended to patients with lumbar disc herniation and pain complaints. Time should be given for the body to regress the lumbar disc herniation with an inflammatory response. Surgery is inevitable in cases of unbearable pain and emergency conditions.
\end{abstract}

Keywords: Lumbar disc herniation, radiculopathy, spontaneous regression

\section{INTRODUCTION}

Lumbar disc herniation occurs due to posterior longitudinal ligament (PLL) rupture, and the symptoms of this condition begin with low back pain ${ }^{(1)}$. It can cause radiculopathy or myelopathy as a result of the nerve root inflammation, with a compression effect due to the disc material ${ }^{(2,3)}$.

Lumbar disc herniation affects approximately $9 \%$ of the world's population ${ }^{(4,5)}$, and it has been observed to increase is with ageing. No specific causes can be found in $85 \%$ of lower back pain $\operatorname{cases}^{(6,7)}$. Of the patients with lumbar disc hernias, 30-40\% are asymptomatic based on imaging ${ }^{(8)}$.

Lumbar herniated nucleus pulposus (LHNP) is most frequently observed at the L5-S1 level (45-50\%), followed by the L4-5 level (40-45\%) and the L3-4 level (3-10\%), respectively ${ }^{(1)}$.

The Lasegue straight leg raising test is positive $(+)$ in $83 \%$ of cases, and this test is sensitive, but not specific ${ }^{(1)}$.

Of all the patients with lumbar disc herniation, only 1-2\% consult surgeons. Cauda syndrome occurs in approximately $0.0004 \%$ of all patients with lower back pain ${ }^{(1)}$.

\section{MATERIALS AND METHODS}

Patients who were admitted to the outpatient clinic with lower back and leg pain were followed-up, and neurological exams were conducted. Patients who needed an emergency surgery were excluded. Medical treatment, painkillers, muscle relaxants, short-term steroids, bed rest and physical therapy were recommended to all the patients. Due to the possible complications of surgery, patients who did not agree to the surgery were advised to undergo a close clinical follow-up. We retrospectively reviewed these patients between March 2017 and March 2019. A total of 20,000 patients were admitted to all the neurosurgery outpatient clinics in the last 3 years, and the mean number of patients who underwent lumbar disc surgery in the last 3 years was 1,200. However, we detected regression only in 12 patients. We discussed the probable mechanisms and predictive factors of lumbar disc resorption. This article received ethical approval from Haseki Research and Training Hospital Ethics Committee (139-17/6/2019), and informed consent was obtained from all the patients. 
turkishspine

\section{Statistical Analysis}

Statistical analysis was performed using SPSS v20.0 (SPSS Inc.). Descriptive data were expressed in terms of frequency, rate, arithmetic mean and standard deviation. Data were analysed using the Student's t-test. A $p$ value of $<0.05$ was considered statistically significant.

\section{RESULTS}

We detected a total of 12 patients with lumbar disc regression, six males and six females, in the last 3 years of follow-up. LHNP was present at the L4-5 space in five patients and at the L5-S1 space in seven patients. Six patients had pain in the right side, while six had pain in the left side (Table 1).

On physical examination, the Lasegue test was positive in all the patients, and six patients had a neurological deficit. The symptoms regressed after medical treatment. In addition, seven patients received physical therapy (Table 1 ).

Eight (62.5\%) of the patients had sequestrated disc herniation, while four had subligamentous disc herniation. Four of the sequestrated discs were up-migrated, while four were downmigrated (Table 1) (Figure 1-12).

The mean age of the patients was $41.83 \pm 6.84$ years. The mean time to pain disappearance of the patients was $2.33 \pm 1.23$ months. The mean time until the control lumbar magnetic resonance imaging (MRI) was $7.16 \pm 6.49$ months.

The independent $t$-test indicated no statistical significance between the sequestrated disc herniation cases in terms of age, gender, side, pain disappearance time and time until the new MRI.

There was no significant correlation between receiving medical or physical therapy and age, gender, pain disappearance time, disc space and undergoing a second MRI.

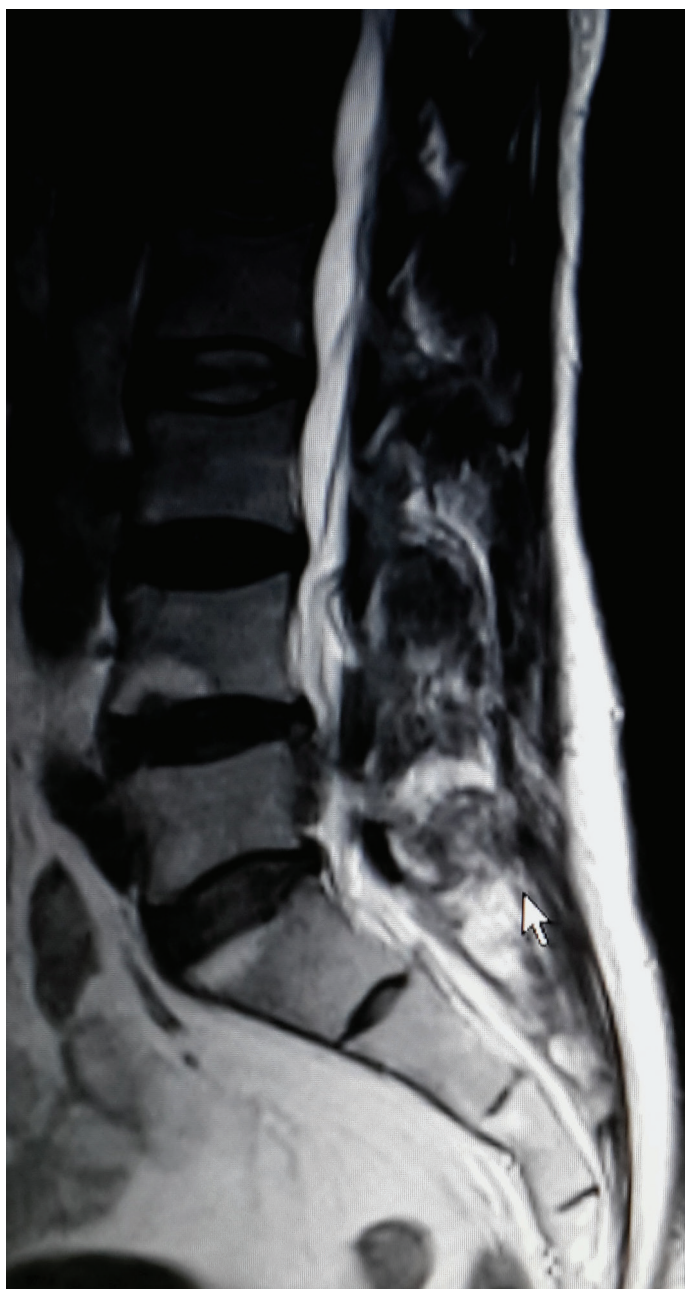

Figure 1. Sagittal T2-weighted MRI demonstrating a large sequestered disc fragment at the L4-5 level with a caudal migration (a 46-year-old female patient with lower back and leg pain) MRI: Magnetic resonance imaging

Table 1. Demographic data

\begin{tabular}{|c|c|c|c|c|c|c|c|c|c|c|}
\hline Age & Sex & Side & Level & SQ & Laseque & $\begin{array}{l}\text { Neurologic } \\
\text { deficit }\end{array}$ & MT & PT & $\begin{array}{l}\text { MRI control } \\
\text { time }\end{array}$ & $\begin{array}{l}\text { Pain loss } \\
\text { time }\end{array}$ \\
\hline 40 & Male & $\mathrm{R}$ & L5-S1 & - & + & - & + & + & 3 & 3 \\
\hline 23 & Male & $\mathrm{L}$ & L5-S1 & - & + & - & + & - & 14 & 3 \\
\hline 39 & Male & $\mathrm{R}$ & L4-5 & + & + & + & + & + & 3 & 3 \\
\hline 44 & Female & $\mathrm{L}$ & L5-S1 & + & + & - & + & - & 3 & 2 \\
\hline 50 & male & $R$ & L4-5 & + & + & + & + & + & 2 & 2 \\
\hline 46 & Female & $L$ & L4-5 & + & + & + & + & - & 6 & 3 \\
\hline 41 & Male & $\mathrm{R}$ & L5-S1 & + & + & - & + & + & 3 & 1 \\
\hline 43 & Female & $\mathrm{L}$ & L5-S1 & - & + & + & + & + & 12 & 5 \\
\hline 40 & Female & $\mathrm{R}$ & L5-S1 & - & + & + & + & - & 6 & 1 \\
\hline 48 & Male & $L$ & L4-5 & + & + & + & + & + & 24 & 1 \\
\hline 46 & Female & $L$ & L4-5 & + & + & - & + & + & 4 & 1 \\
\hline 42 & Female & $\mathrm{R}$ & L5-S1 & + & + & - & + & - & 6 & 3 \\
\hline
\end{tabular}

R: Right side, L: Left side, SQ: Sequestration, MT: Medical therapy, PT: Physical therapy, L5-S1: Lumbar level (L), sacral (S) 


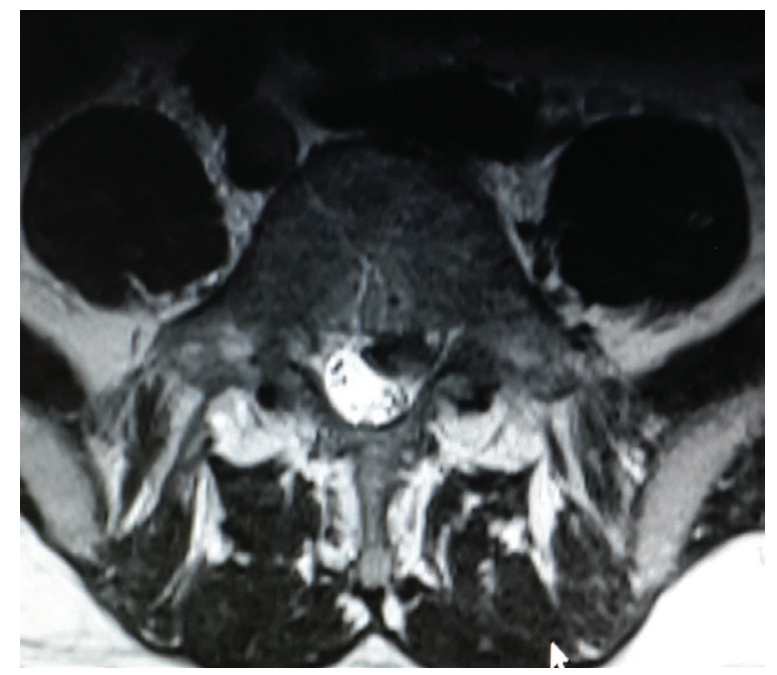

Figure 2. Axial T2-weighted MRI demonstrating a large sequestered left-sided paracentral disc fragment at the L4-5 level (pain relievers, muscle relaxants and bed rest were recommended to the patient

MRI: Magnetic resonance imaging

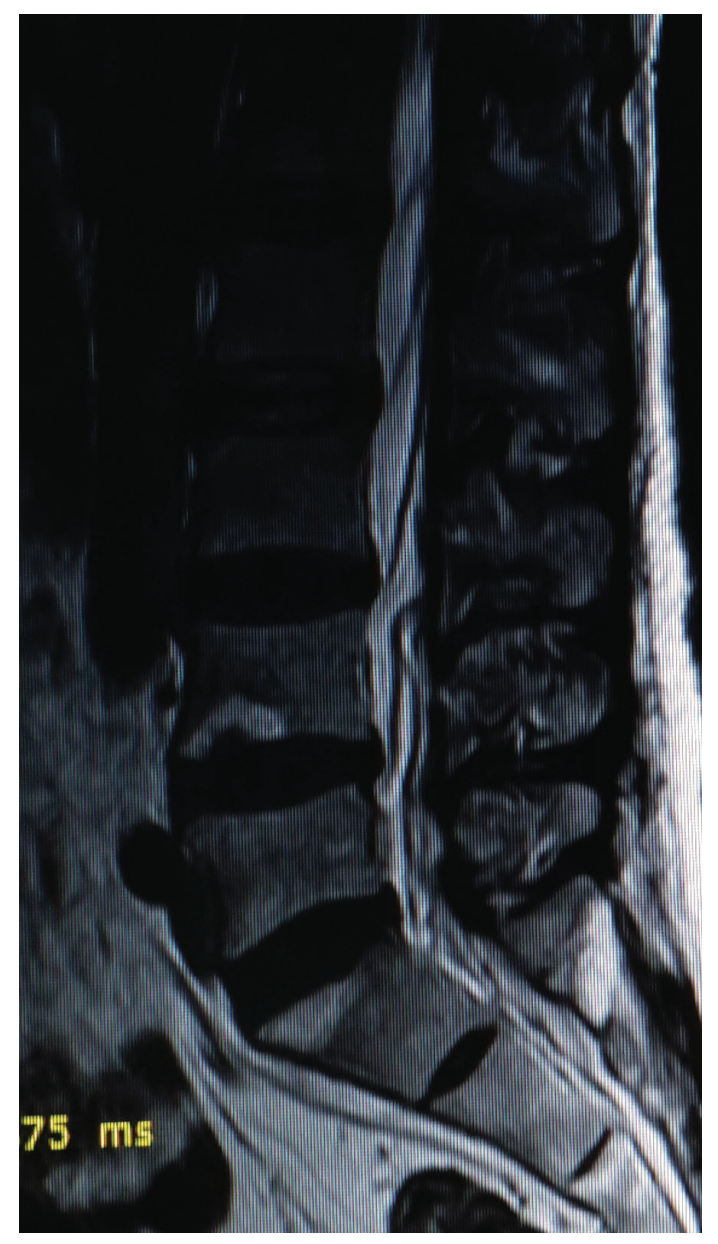

Figure 3. Sagittal T2-weighted second round MRI showed almost complete regression of the herniated nucleus pulposus at the L4-5 level (her complaints were resolved 12 weeks later) MRI: Magnetic resonance imaging

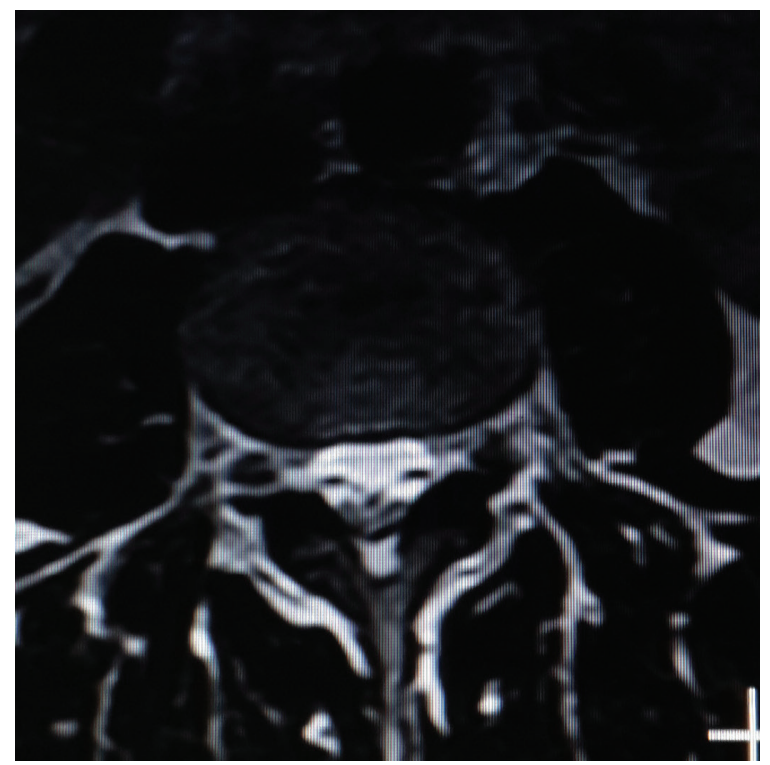

Figure 4. Axial T2-weighted second round MRI showed almost complete regression of the herniated nucleus pulposus at the L4-5 level without nerve root compression MRI: Magnetic resonance imaging

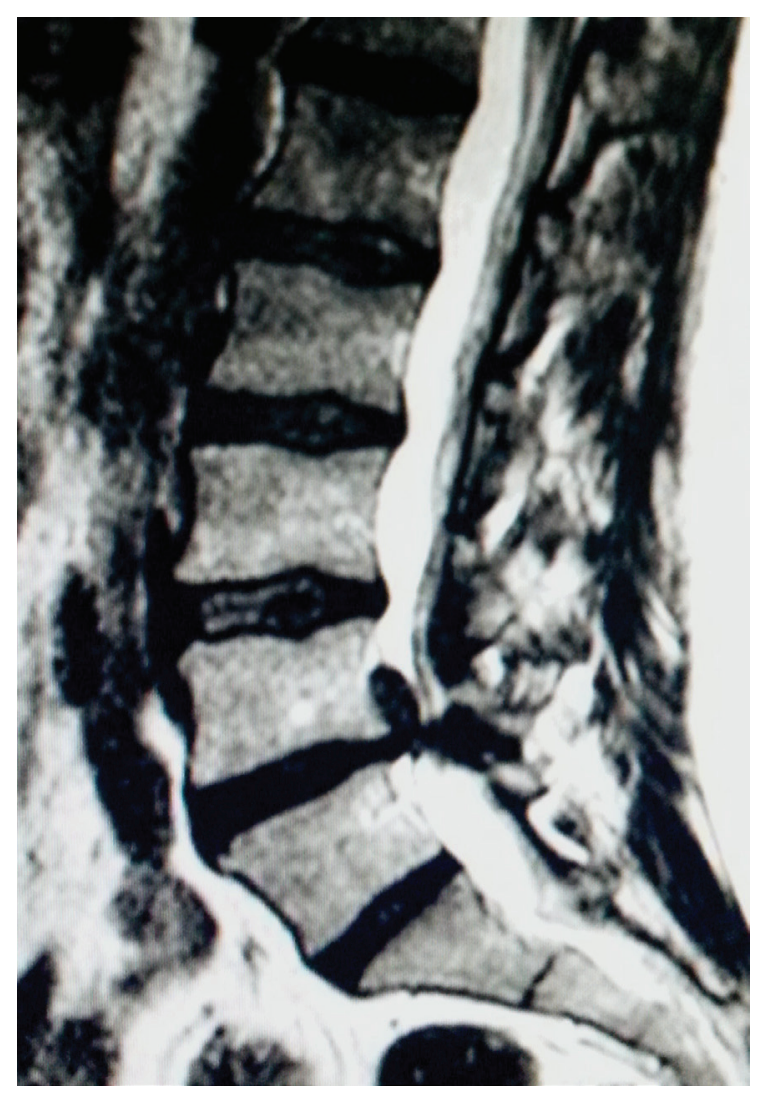

Figure 5. Sagittal T2-weighted MRI showed cranial migration of the herniated nucleus pulposus at the L4-5 level (a 48-year-old male patient with complaints of lower back pain and left-sided sciatalgia)

MRI: Magnetic resonance imaging 


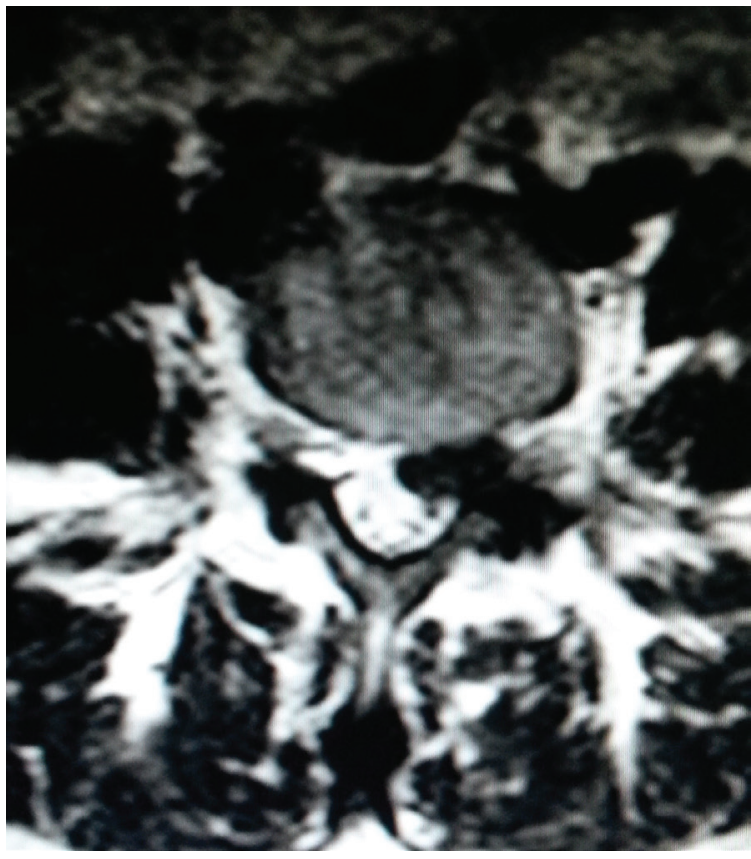

Figure 6. Axial T2-weighted MRI showed left-sided posterolateral extruded disc fragment at the L4-5 level (a 48-year-old male with axial sign; physical therapy was recommended after medical treatment)

MRI: Magnetic resonance imaging

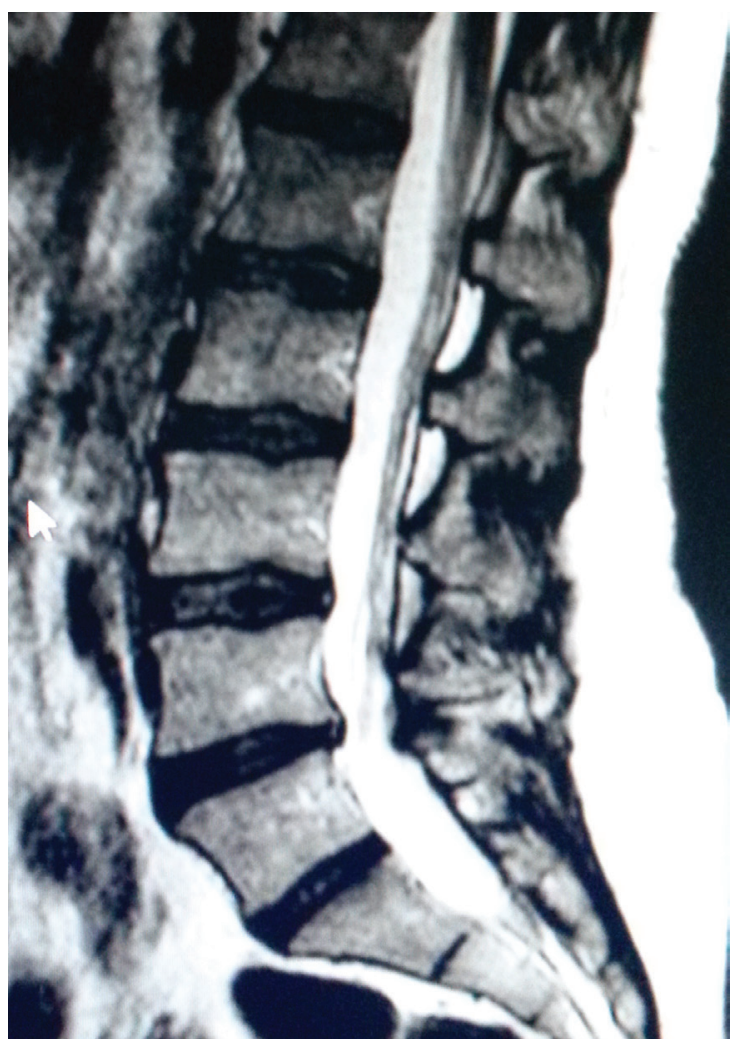

Figure 7. Control sagittal T2-weighted MRI showed almost complete regression of the herniated nucleus pulposus at the L4-5 level (his pain disappeared after a month; he came for control 24 months later)

MRI: Magnetic resonance imaging

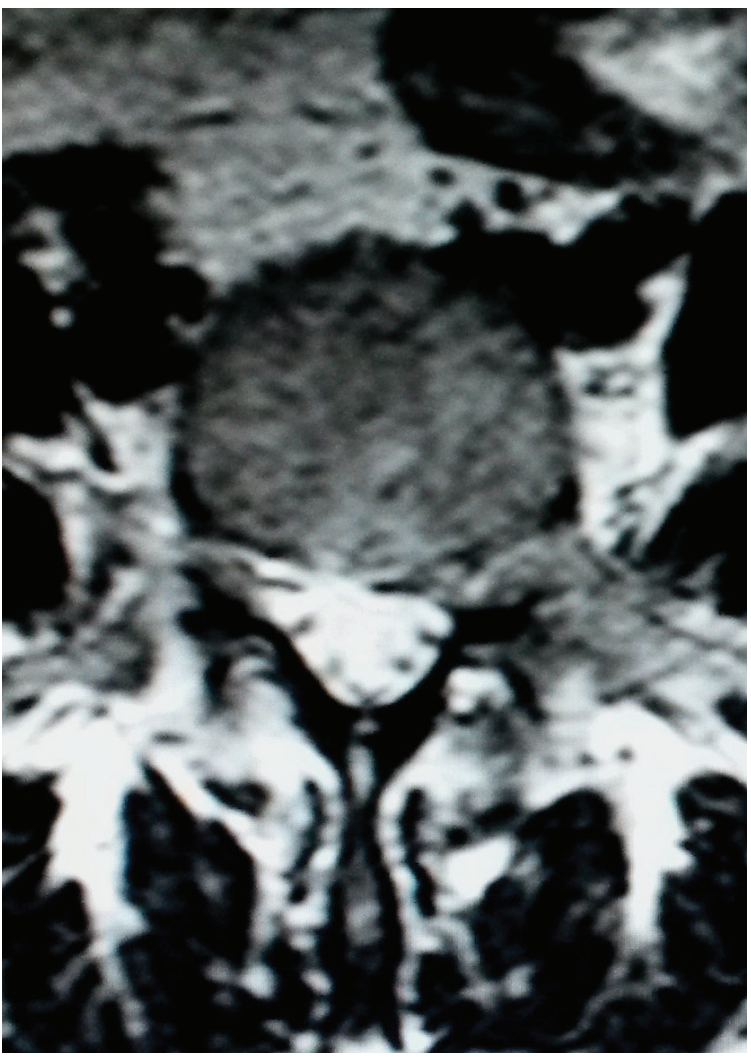

Figure 8. Control axial T2-Weighted MRI showed almost complete regression of the herniated nucleus pulposus at the L4-5 level MRI: Magnetic resonance imaging

\section{DISCUSSION}

Over $90 \%$ of lumbar disc patients who develop acute radiculopathy can recover without the need for any surgical intervention. The painful phase can be made more tolerable with adequate pain relievers, muscle relaxants, short-term steroids and bed rest during the recovery period $\mathrm{d}^{(1,6,9)}$.

Partial or complete regression of lumbar disc herniation has been reported in the literature. The most frequently affected space is the L4-5 space ${ }^{(10)}$.

The regression is accelerated young patients, and the recovery rate is the fastest between the ages of 41 and $50^{(10)}$.

Protruded and sequestered discs show rapid regressions. Large and sequestered discs tend to regress more easily than smaller and protruded discs, if they are laterally located with a craniocaudal migration ${ }^{(2,6,10-14)}$.

The mechanism of spontaneous disc herniation has many uncertain factors. These factors include the age of the patient, dehydration of the nucleus pulposus, resorption of a hematoma, revascularisation, HNP, PLL, cartilage and annulus fibrosus $(2,4,6,6,11)$. There are several mechanisms of spontaneous disc herniation. The disc material is reduced with dehydration and shrinkage as observed by MRI ${ }^{(15,16)}$. The PLL retracts the herniated disc back ${ }^{(4)}$. The enzymatic effect, inflammation, neovascularisation and phagocytosis stand out in preclinical and clinical evidence ${ }^{(12-14)}$. 


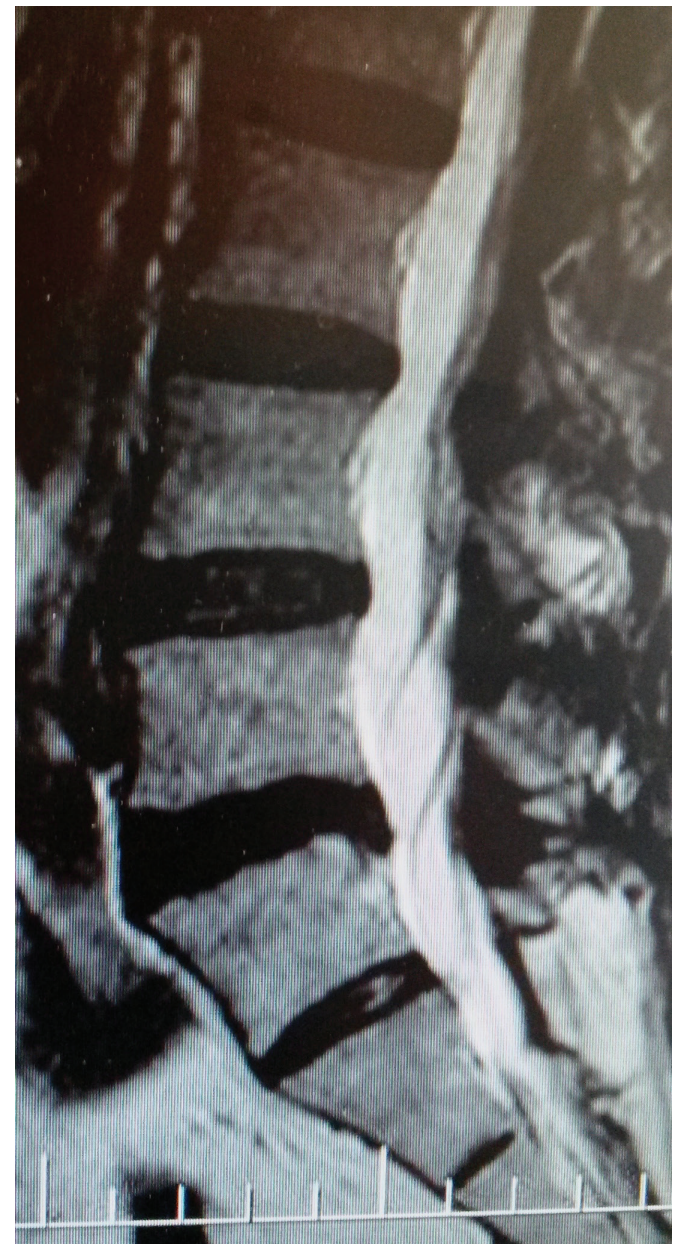

Figure 9. Sagittal T2-weighted MRI showed signs of a caudal migrated disc fragment at the L5-S1 level (a 41-year-old male with right leg pain)

MRI: Magnetic resonance imaging

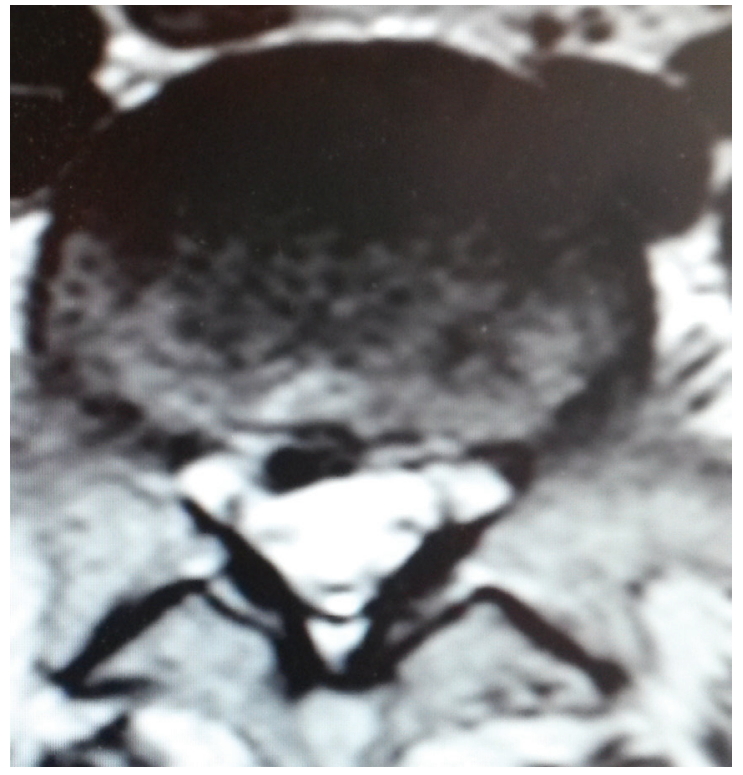

Figure 10. Axial T2-weighted MRI showed signs of right paracentral side disc fragment at the L5-S1 level (a 41-year old) MRI: Magnetic resonance imaging

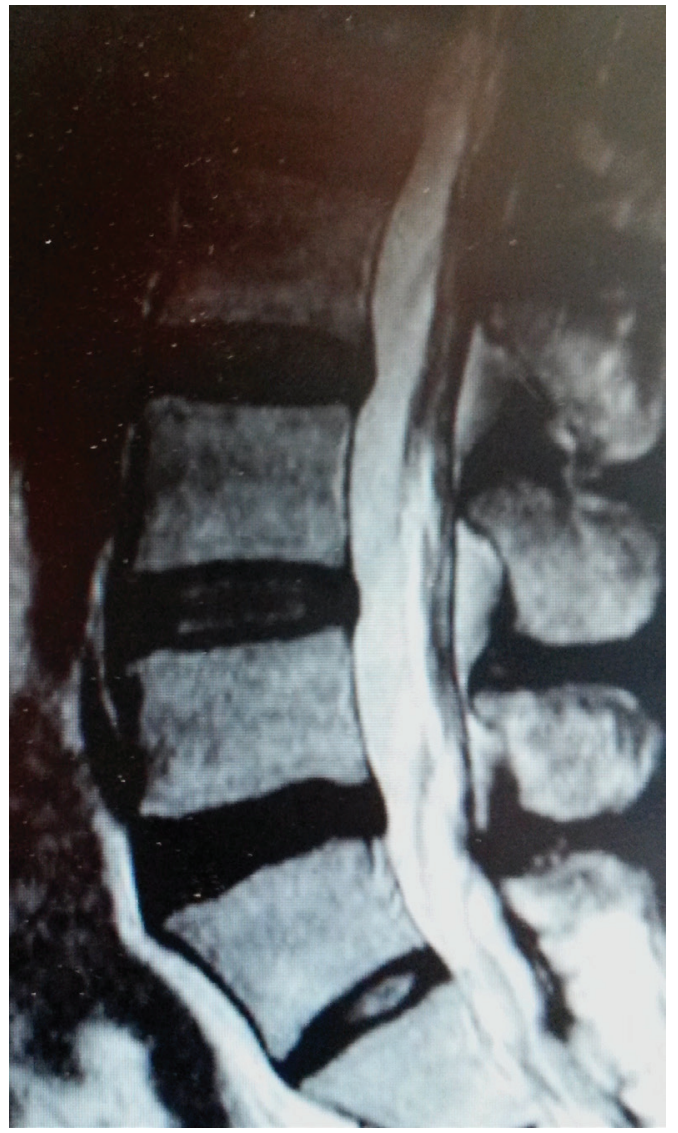

Figure 11. Sagittal T2-weighted MRI showed signs of complete regression of the herniated nucleus pulposus (in the third month, his neurological examination was normal, his muscle strength was full in the outpatient control visit in our neurosurgery department and the disc was observed to have regressed on the control MRI in the third month control visit) MRI: Magnetic resonance imaging

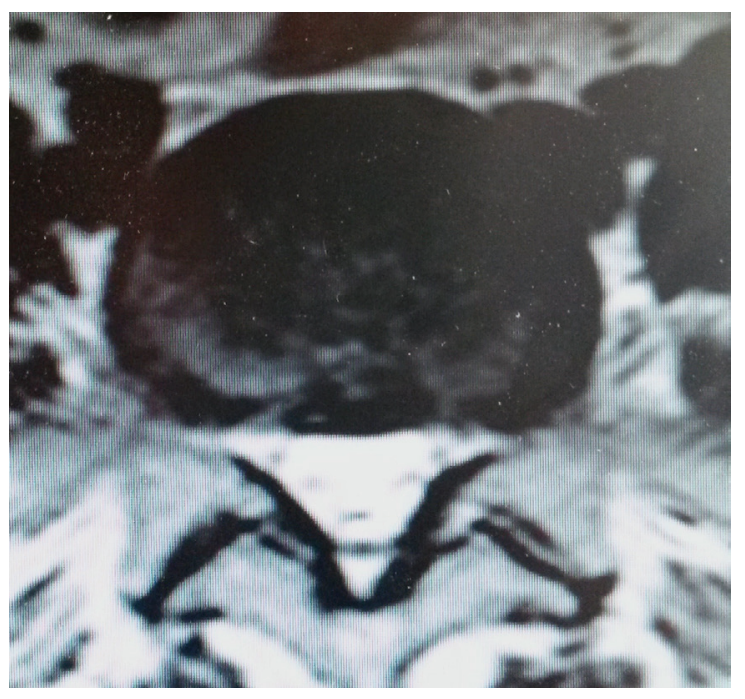

Figure 12. Axial T2-weighted MRI showed signs of complete regression of the herniated nucleus pulposus (the patient's third month control axial sign)

MRI: Magnetic resonance imaging 
The intervertebral disc region is the largest avascular organ and an immune-privileged site of the body. Fas ligand belongs to the apoptosis group of the tumour necrosis factor (TNF) family and is affected by cytotoxic T cells and natural killer cells $s^{(15-17)}$. Macrophages are the key players. They induce phagocytosis by releasing enzymes from their lysosomes ${ }^{(18,19)}$. The exact role of monocytes in the intervertebral disc has not yet been elucidated. Monocyte chemoattractant protein-1 (MCP-1) allows macrophages to infiltrate the disc ${ }^{(4,20,21)}$. Immune mediators in the intervertebral disc are interleukin (IL)-6, 8, 4 and 12; NO; prostaglandin E2; matrix metalloproteinase-2,3,7 and 9; interferon- $\alpha$ and $\gamma$ and MCP-1 $1^{(19,20,22-25)}$. They appear with matrix remodelling and angiogenesis in the neovascularisation and inflammation cascade ${ }^{(4)}$. CD $68(+)$, macrophages and B lymphocytes are involved in the disc herniation. TNF- $\alpha$ and IL-1 $\beta$ are released on the first day, while MCP-1 is released on the third day ${ }^{(4)}$. Disc regression is caused by pulsation of the cerebrospinal fluid to the herniated parts ${ }^{(11,26,27)}$.

PLL rupture is more important than the disc size. The subligamentous, transligamentous and sequestrated disc regression rates can be $17 \%, 48 \%$ and $82 \%$, respectively ${ }^{(4,26,28,29)}$. Three percent of all discs are sequestrated, and sequestrated discs are more likely to be regressed compared to other discs. These discs are up-migrated by $65 \%$. Of the cases with regressed lumbar discs, $37.7 \%$ are sequestrated. Sequestrated discs are most frequently seen at the L4-5 space (58.3\%), followed by the L5-S1 (25\%) and the L3-4 spaces (12.5\%) $)^{(10,28-34)}$.

As for our cases, L4-5 HNP was observed in seven lumbar discs, while L5-S1 HNP was observed in five lumbar discs.

The L4-5 space was affected in five of the sequestrated disc patients, while the L5-S1 space was affected in four of them. In addition, the L4-5 space was affected more in our patient group. Discs were superiorly migrated in four cases and caudally migrated in four cases (50\%).

A sequestrated disc was separated from the main disc material in the lumbar region. An intraspinal mass can be observed as a cyst, abscess or hematoma, and should also be considered in the differential diagnosis ${ }^{(10)}$.

Sequestrated disc dehydration and shrinkage are seen radiologically at a faster improvement rate. Like a free fragment, a sequestrated disc rapidly increases inflammation and activates vascularity and the immune system ${ }^{(4,10)}$.

In the literature, pain occurring among cases with regressed lumbar disc herniation has been reported to disappear after $1.33 \pm 1.34$ months, and radiological recovery was achieved in $9.27 \pm 13.32$ months. In our series, the mean time to pain disappearance of the patients was $2.33 \pm 1.23$ months, while the mean time until the control lumbar MRI was $7.16 \pm 6.49$ months.

\section{Study Limitations}

On the other hand, this study has limitations such as the small sample size, short follow-up period and retrospectively design.
In addition, none of the patients could be randomised to a treatment, and there were no control subjects.

Surgical intervention is the preferred method of treatment in patients with larger herniated discs imaged on MRI and associated with radiculopathy, myelopathy or both. Emergency surgery is planned in cases of persistent pain, conditions that negatively affect social life, foot drop, urinary and stool incontinence or cauda conditions.

\section{CONCLUSION}

Bed rest and conservative treatment are primarily recommended to patients with lumbar disc herniation. Time should be given for the body to regress the lumbar disc herniation with an inflammatory response. Surgery is inevitable in cases of unbearable pain and emergency conditions.

\section{Ethics}

Ethics Committee Approval: Ethical approval has taken for the retrospective study from Haseki Research and Training Hospital Ethics Committee (139-17/6/2019).

Informed Consent: Informed consent was obtained from the patients.

Peer-review: Internally peer-reviewed.

\section{Authorship Contributions}

Concept: A.A., N.A., B.M.K., Design: A.A., N.A., Data Collection or Processing: A.A., N.A., B.M.K., Analysis or Interpretation: A.A., M.K., Literature Search: A.A., M.K., Writing: A.A.

Conflict of Interest: No conflict of interest was declared by the authors.

Financial Disclosure: The authors declared that this study received no financial support.

\section{REFERENCES}

1. Greenberg MS. Handbook of Neurosurgery. 6th edition. Thieme medical publisher 2006;pp:289-312.

2. Yang X, Zhang Q, Hao X, Guo X, Wang L. Spontaneous regression of herniated lumbar discs: report of one illustrative case and review of the literature. Clin Neurol Neurosurg. 2016;143:86-9.

3. Hasegawa T, An HS, Inufusa A, Mikawa Y, Watanabe R. The effect of age on inflammatory responses and nerve root injuries after lumbar disc herniation: an experimental study in canine model. Spine. 2000;8:937-40.

4. Cunha C, Silva AJ, Pereira P, Vaz R, Gonçalves RM, Barbosa MA. The inflammatory response in the regression of lumbar disc herniatian review. Arthritis Res Ther. 2018;20:251.

5. Hoy D, March L, Brooks P, Blyth F, Woolf A, Bain C, et al. The global burden of low back pain: estimates from Global Burden of Disease 2010 study. Ann Rheum Dis. 2014;73:968-74.

6. Çitişli V, Ibrahimoğlu M. Spontaneous remission of a big subligamentous extruded disc herniation : case report and review of the literature. Korean J Spine. 2015;12:19-21.

7. Ribeiro RP, Matos RM, Vieira A, Costa JM, Proença R, Pinto R. Spontaneous regression of symptomatic lumbar disc herniation. Acta Rheumatol Port. 2011;36:396-8.

8. Brinjikji W, Luetmer PH, Comstock B, Bresnahan BW, Chen LE, Deyo RA, et al. Systematic literature review of imaging features of spinal degeneration in asymptomatic populations. Am J Neuroradiol. 2015;36:811-6. 
9. Gezici AR, Ergün R. Spontaneous regression of a huge subligamentous extruded disc herniation: short report of an illustrative case. Acha Neurochir. 2009;151:1299-300.

10. Macki M, Hernandez-Hermann M, Bydon M, Gokaslan A, McGovern K, Bydon A. Spontaneous regression of sequestrated lumbar disc herniations: literature review. Clin Neurol Neurosurg. 2014;120:136-41.

11. Orief T, Orz Y, Attia W, Almusrea K. Spontaneous resorption of sequestrated intervertebral disc herniation. World Neurosurg. 2011;77:146-52.

12. Autio RA, Karppinen J, Niinimaki J, Ojala R, Kurunlahti M, Haapea M, et al. Determinations of spontaneous resorption of intervertebral disc herniations. Spine. 2006;31:1247-52.

13. Kobayashi S, Meir A, Kokubo Y, Uchida K, Takeno K, Miyazaki T, et al. Ultrastructural analysis on lumbar disc herniation using surgical specimens: role of neovascularization and macrophages in hernias. Spine. 2009;34:662-5.

14. Yoshida M, Nakamura T, Sei A, Kikuchi T, Takagi K, Matsukawa A. Intervertebral disc cells procedure tumor necrosis factor alpha, interleukin1 beta, and monocyte chemoattractant protein-1 immediately after herniation: an experimental study using anew hernia model. Spine. 2005;30:55-61.

15. Hiyama A, Mochia J, Sakai D. Stem cell applications in intervertebral disc repair. Cell Mol Biol. 2008;54:24-32.

16. Takada T, Nishida K, Doita M, Kurosaka M. Fas ligand exists on intervertebral disc cells: a potential molecular mechanism for immune privilege of the disc. Spine. 2002;27:1526-30.

17. Green DR, Ferguson TA. The role of Fas ligand in immune privilege. Nat Rev Mol Cell Biol. 2001;2:917-24.

18. Koike Y, Uzuki M, Kokubun S, Sawai T. Angiogenesis and inflammatory cell infiltration in lumbar disc herniation. Spine. 2003;28:1928-33.

19. Shamji MF, Setton LA, Jarvis W, So S, Chen J, Jing L, et al. Proinflammatory cytokine expression profile in degenerated and herniated human intervertebral disc tissues. Arthritis Rheum. 2010;62:1974-82.

20. Burke JG, Watson RW, McCormack D, Dowling FE, Walsh MG, Fitzpatrick JM. Spontaneous production of monocyte chemoattractant protein-1 and interleukin -8 by the human lumbar intervertebral disc. Spine. 2002;27:1402-7.

21. Yoshida M, Nakamura T, Kikuchi T, Takaghi K, Matsukawa A. Expression of monocyte chemoattractant protein-1 in primary cultures of rabbit intervertebral disc cells. J Orthop Res. 2002;20:1298-304.

22. Takada T, Nishida K, Doit M, Miyamato H, Kurosaka M. Interleukin-6 production is up-regulated by interaction between disc tissue and macrophages. Spine. 2004;29:1089-92.
23. Takada T, Nishida K, Maeno K, Kakutani K, Yurube T, Doita M, et al. Intervertebral disc and macrophage interaction induces mechanical hyperalgesia and cytokine production in herniated disc model in rats. Arthritis Rheum. 2012;64:2601-10.

24. Haro H, Crawford HC, Fingleton B, MacDougall JR, Shinomiya K, Spengler DM, et al. Matrix metalloproteinase-3-dependent generation of a macrophage chemoattractant in a model of herniated disc resorption. J Clin Invest. 2000;105:133-41.

25. Haro H, Crawford HC, Fingleton B, Shinomiya K, Spengler DM, Matrisian LM. Matrix metalloproteinase-7-dependent release of tumor necrosis factor-alpha in a rat model of herniated disc resorption. J Clin Invest. 2000;105:143-50.

26. Ahn S, Ahn M, Byun W. Effect of transligamentous extension of lumbar disc herniations on their regression and clinical outcome of sciatica. Spine. 2000;25:475-80.

27. Martinez-Quiñones JV, Aso-Escario J, Consolini F, Arregui-Calvo R. Spontaneous regression from intervertebral disc herniation. Propos of a series of 37 cases. Neurocirugia (Astur). 2010;21:108-17.

28. Takada E, Takahashi M, Shimada K. Natural history of lumbar disc hernia with radicular leg pain: spontaneous MRI changes of herniated mass and correlation with clinical outcome. J Orthop Surg(Hong Kong). 2001;36:416-9.

29. Fardon DF, Milette PC. Nomenclature and classification of lumbar disc pathology. Recommendation of the combined task forces of the North American Spine Society, American Society of Spine Radiology, and American Society of Neuroradiology. Spine. 2001;26:E93-113.

30. Albert HB, Manniche C. The efficacy of systematic active conservative treatment for patients with severe sciatica: a single-blind, randomized, clinical, controlled trial. Spine. 2012;37:531-42.

31. Ahn SH, Park HW, Byun WM, Ahn MW, Bae JH, Janget $\mathrm{SH}$, et al. Comparison of clinical outcomes and natural morphologic changes between sequestered and large central extruded disc herniations. Yonsei Med J. 2002;43:283-90.

32. Weinstein JN, Lurie JD, Tosteson TD, Skinner JS, Hanscom B, Tostesonet ANA, et al. Surgical vs nonoperative treatment for lumbar disc herniation: the spine patient outcomes research trial (sport) observational cohort. JAMA. 2006;296:2451-9.

33. Gelabert-Gonzalez M, Serramito-Garcia R, Aran-Echabe E, GarciaAllut A. Spontaneous resolution of a lumbar disc herniation. Neurochirurgica. 2009;151:1299-300.

34. Chiu CC, Chuang TY, Chang KH, Wu CH, Lin PW, Hsu WY. The probability of spontaneous regression of lumbar herniated disc: a systematic review. Clin Rehabil. 2015;29:184-95. 